\title{
Husbandry and reproduction of the Saharan spiny-tailed lizard, Uromastyx geyri
}

\author{
ADAM RADOVANOVIC \\ Birmingham Wildlife Conservation Park, Pershore Road, Edgbaston, B5 7RL \\ Authore-mail: rad_backinblack@hotmail.co.uk
}

\section{INTRODUCTION}

$\mathrm{T}$ he Saharan or Geyr's spiny-tailed lizard, Uromastyx geyri (Muller, 1922) is a relatively small lizard (Schleich et al., 1996) with a maximum total length of $35.5 \mathrm{~cm}$ of which $45 \%$ is tail (Wilms et al., 2009). It is endemic to the Hoggar and Air mountains of north-east Mali and southern Algeria where it inhabits rocky outcrops. Colour can range from magnificent cinnabar red or bright yellow with blackish brown squiggles (Wilms, 2005). The species is assessed as Near Threatened and populations are in decline (Wilms et al., 2018). All species within the genus Uromastyx are hunted for food, souvenirs and traditional medicine (Wilms, 2007). Uromastyx geyri is one of nine species of Uromastyx to be affected by the international pet trade and due to their commercial value are listed in Appendix II of CITES (2020).

Little information is available on the ecology, captive maintenance and breeding of U.geyri (Wilms, 2005). This article presents the first experiences of the Birmingham Wildlife Conservation Park (BWCP) in maintaining and breeding the species.

\section{METHODS \& MATERIALS}

\section{Livestock}

In 2015, four male and one female sub-adult wild caught $U$. geyri were acquired by BWCP following a confiscation. Two of the males were high orange/red and two males were high yellow (Fig. 1). The female had light orange markings on the dorsum. The ventral surface of female $U$. geyri is pale and uniform in colour unlike the males in which the dorsal coloration and markings continue onto the ventral surface. The males weighed between 220-240 g and the female weighed $182 \mathrm{~g}$ at the beginning of February 2016.

\section{Enclosure and heating}

The lizards were housed together in a $120 \times 60 \times 60 \mathrm{~cm}$ plastic moulded Vision Cage (Fig. 2). Three Arcadia $160 \mathrm{~W}$ basking lamps were used as sources of heat, visible light and UVB radiation. The lamps were installed to heat the enclosure efficiently and spaced away from each other to prevent antagonistic behaviour between male lizards. The substrate was a mixture of bird sand and coco-fibre (ratio 4:1) which was approximately $6-8 \mathrm{~cm}$ deep. Various sized sandstone rocks were positioned under the basking areas at various heights (Fig. 1) to provide gradients of heat and UVB. Two pieces of driftwood were positioned higher than the rocks but away from the basking areas to provide climbing opportunities and to increase usable enclosure space. Pieces of curved tree bark was placed on the substrate to act as refuges. A small ceramic bowl contained water.
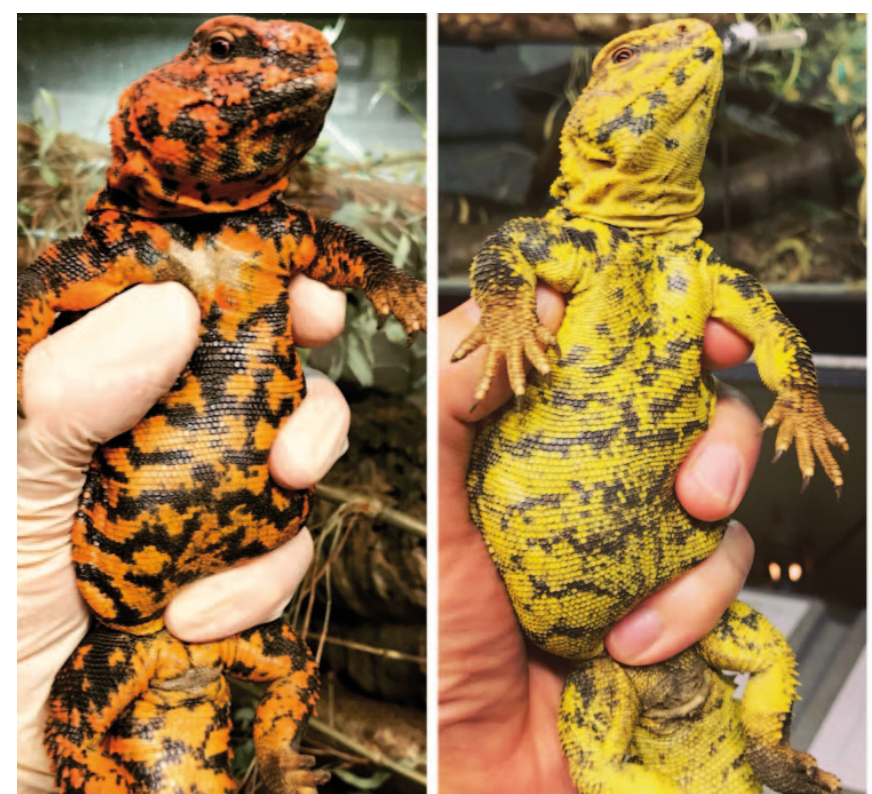

Figure 1. Red male (left) and yellow male (right) U. geyri

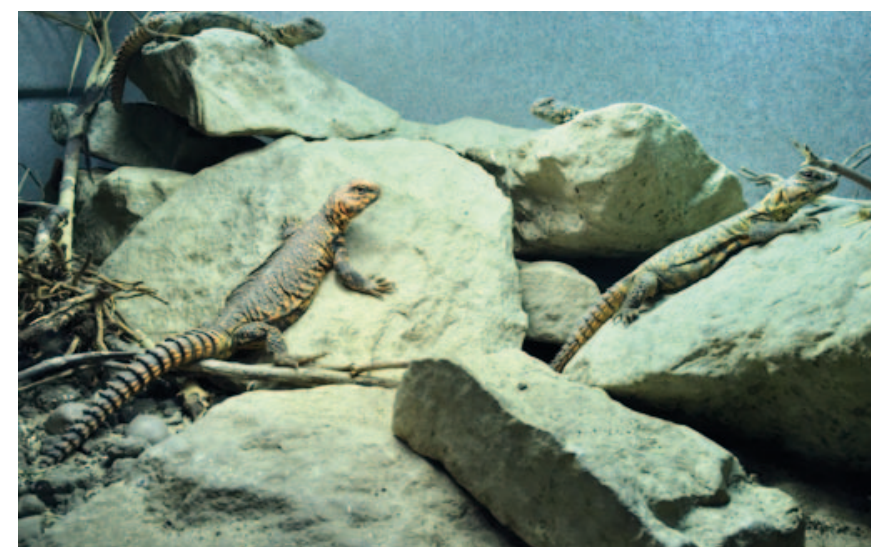

Figure 2. Basking area of the enclosure holding an adult group of four male and one female $U$. geyri. The enclosure was also furnished with drift wood and pieces of curved bark to the right but out of view in this image. 
The enclosure was maintained on a 12/12 light/dark cycle throughout the year. Temperatures and humidities in the enclosure were measured using a max-min thermohygrometer, spot temperatures recorded using an infrared temperature gun (IR Laser Point Version 320EN-00), and UV index assessed using a Solarmeter 6.5 UVI radiometer. Ambient daytime temperature ranged from 28$35{ }^{\circ} \mathrm{C}$, basking temperature was $45-50{ }^{\circ} \mathrm{C}$ with the surface temperature of the rocks occasionally reaching $55{ }^{\circ} \mathrm{C}$, and the UV Index was 6-8 at a position equivalent to the dorsum of a basking lizard. Night temperatures were between 20-22 ${ }^{\circ} \mathrm{C}$. Humidity was maintained at $20-40 \%$ RH but occasionally reached $70 \%$ after weekly substrate sprays. Specimens hid between the rocks during spraying but would soon come out to resume basking and were occasionally observed drinking. From November to January, night time temperatures were gradually reduced to $14-16{ }^{\circ} \mathrm{C}$, the rest of the temperature profile remained unchanged. During these months, the group of $U$. geyri were active for shorter periods during the day and they didn't begin basking until midday. Night time temperatures were gradually increased over a period of two weeks in February; at this point all specimens began basking from 09.00h.

\section{Food and feeding adjustments}

From spring to autumn (March - October), the lizards were fed dandelion leaves and flowers, broad and narrow leaf plantain, sow thistle and clover. These were picked fresh from the zoo grounds and were presented 4-5 times per week. When fresh weeds were not available during the winter months, they were substituted by a mixture of endive lettuce, coriander, water and mustard cress, grated carrot and chicory (3-4 times per week). A dietary supplement Nutrobal (Vetark) was sprinkled over the food once per week. This is a multi-vitamin supplement containing calcium and the following vitamins $A, C, E, D 3, K 3$, and the $B$ group. Live invertebrates were readily accepted with locust, Locusta migratoria (small and large sized) being the most favoured. All live food was dusted with Nutrobal and fed to the group once every two weeks. Tidymix Pulse \& Rice Soaking Parrot Food (Tidy Mix Diets) that had been soaked for $48 \mathrm{~h}$ were fed to the lizards once, every 3-4 weeks. The product contains the following pulses - soya, adzuki, mung, pinto, blackeye, haricot beans, chickpea, green and yellow peas, puy $\&$ red lentils, as well as the cereals wheat and brown rice.

From November to January, when night time temperatures were reduced, food portions were reduced by about $50 \%$ and as the night time temperatures were gradually increased in February, the amount of food offered was also increased back to normal.

\section{Incubation of eggs}

An opaque plastic box ( $30 \times 20 \times 20 \mathrm{~cm}$ ) was provided for egg laying. A hole was cut into the lid to allow access for the female and the box was filled to a depth of about 15 $\mathrm{cm}$ with damp coco-fibre. Rocks were built up around the box to allow ease of access and the area by the hole was covered with bark for seclusion. After oviposition, eggs were transferred to a clear air-tight plastic box that fitted into a large neonatal incubator (Vickers Medical Model 79 Servo). Fine grade vermiculite mixed with water (ratio 3:1) was used as the incubating medium. The eggs were very soft and care was taken during the transfer. Eggs were half buried in the medium and damp sphagnum moss was added to all corners of the box for extra humidity. Eggs were incubated at $30.5^{\circ} \mathrm{C}$ and relative humidity ranged from 90-95\%, measured using a max-min thermohygrometer with a probe going directly into the box. After 14 days of incubation, eggs were candled using a torch to observe vascularity as evidence of viability. The eggs were aired every three to four days by lifting the lid of the box.

\section{Rearing hatchlings}

Once hatchlings were free from the eggs, they were transferred to a plastic container supplied with damp kitchen towel and left for approximately two days post emergence. This was enough time for the umbilicus to dry up. They were then transferred to a rearing tank (Exo-Terra Turtle Terrarium, $90 \times 45 \times 45 \mathrm{~cm}$ ). All environmental parameters were the same as for the adults. At 5-7 days post emergence, the hatchlings were fed daily on the same mix of food as the adults. Small locusts were taken readily and nuts and pulses were soaked for $48 \mathrm{~h}$ and then crushed before offering. Food was scattered all over the rocks to ensure all individuals could feed. A small pinch (not measured) of Nutrobal was added to the food and occasionally sprinkled over the rocks once every 7-10 days. The rocks were sprayed with water daily and the hatchlings were often observed running over to the wet surface to drink. This behaviour lasted for about two months after which the hatchlings retreated whenever the enclosure was sprayed.

\section{OBSERVATIONS AND DISCUSSION}

\section{Reproductive behaviour}

From November 2015 to January 2016, males were noticeably active and displayed dominant gestures such as head bobbing, hissing, body arching and circling on the spot. These displays would occasionally escalate and the dominant male would climb onto the other males and circle on top of them. The submissive male(s) would either retreat or remain motionless. Occasionally biting was observed and this resulted in superficial marks to the neck and flanks. Submissive males continued to eat and bask. Copulation between the dominant male and the female was only observed on 21st February. On the 3rd April, the female was observed basking earlier than usual and for extended periods during the day. This raised her body temperature to 45-48 ${ }^{\circ} \mathrm{C}$. Once these temperatures had been reached the female would move in and out of the basking zones to maintain this temperature. This behaviour was observed until oviposition. During gestation, eggs were visible laterally when the female was basking. On the 1st April, the egg laying box was placed in the enclosure and on 15th April the female entered the box and was observed digging and moving substrate. This happened for 3-5 minutes and then the female would retreat. This behaviour continued and was rather sporadic for the next few days. The temperature in the box ranged from 
$28-32{ }^{\circ} \mathrm{C}$. On 20th April, the female was seen egg-laying in the box for about 90 minutes and laid eleven eggs. Three eggs were discolored and waxy in appearance and were deemed infertile and immediately discarded. Following oviposition, the female looked emaciated but was still active and alert.

\section{Incubation of eggs and hatching}

On day 8 of incubation, two of the eggs began to discolour and sweat. They were left for a further two days, after which they had completely desiccated. Both eggs were removed. Fifty-two days into incubation another egg began to sweat and discolour. The shape of the egg was still spherical, so it was decided to wipe away the excess water and wrap the egg in kitchen towel. Four days later the egg was emitting a foul smell, so it was decided to cut open the egg. On doing this, a dead and premature embryo was revealed. It was then decided to place a plastic egg crate between the remaining five eggs and vermiculite (Fig. 3). The incubation substrate could then be flooded with water to increase humidity without the eggs coming into direct contact with water/excess moisture (Basford, L. pers.comm). On day 91 of incubation, one of the eggs pipped at around 11:00h (Fig. $3 \mathrm{~A})$. The specimen was only halfway out of the egg by $17.00 \mathrm{~h}$ and looked exhausted. On day 92, the first hatchling was completely out of the egg and two more eggs had pipped. On day 93, three hatchlings were completely out of the egg. On day 94, a noticeably smaller hatchling had emerged from one of the eggs. Under closer inspection, it was a twin. The other specimen had died and was fully formed (Fig. 3B). On day 96, five days after the first specimen hatched, it was decided to cut open the final egg using a scalpel. A blunt snake probe was used to gently touch the specimen to determine life and movement inside the egg was observed. It was decided to totally remove the fully-formed live foetus from the egg and place it in a separate container with some damp kitchen towel. After $24 \mathrm{~h}$ the hatchling had separated from its umbilicus and was introduced to the others.

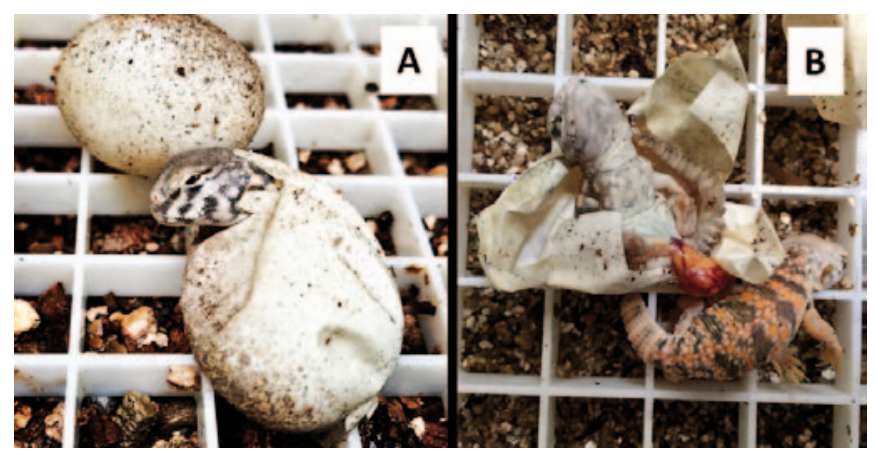

Figure 3. Eggs of $U$. geyri in the incubation box with an egg crate separating the eggs from the incubation medium $\mathbf{- A}$. The first egg to pip, and $\mathbf{B}$. An egg containing twins

\section{Rearing the hatchlings}

Hatchlings were too small to sex accurately before they were moved to other zoological collections. They weighed 5.6-6.5 $\mathrm{g}$ at birth with the live twin weighing $2.9 \mathrm{~g}$ and the dead twin weighing $2.3 \mathrm{~g}$. After 28 days, the other twin died but all the other hatchlings survived to the time that they were dispatched to other collections and at the time of writing (after about four years) they are all apparently still alive.

\section{Lesson learnt}

Incubation of eggs: To incubate a clutch of $22 U$. geyri eggs, Turnbull (2012) used a particularly high proportion of water in the incubation medium, vermiculite to water (1:5). Half of the eggs succumbed to mould and splitting and only four hatched successfully. In our subsequent breeding programmes, we have continued to use a vermiculite to water ratio of 3:1 and continue to separate the eggs and incubation medium with plastic egg crates. This has improved our hatch rate. In 2017, we hatched a total of six individuals from seven fertile eggs and in 2018 we hatched a total of seven from eight fertile eggs.

Feeding: At the time the $U$. geyri were acquired there was no published recommendation for a suitable feeding regime. When we compared photographs of wild animals with captive animals we suspected that many captive Uromastyx species were overweight. We therefore adopted an approach of increasing the intervals between feeds and of reducing portion sizes which seemed to produce healthier and more active animals. After oviposition, it is important to feed the females daily as they are emaciated and need good nutrition to recover and be healthy enough to reproduce annually. At this time, males were usually removed from the enclosure to prevent them eating too much and to accurately monitor the females' food consumption.

General husbandry: Copulation has only been observed at one time of the year and so leaving the female with the males in the group after oviposition did not present a problem.

During the winter months, it was decided to only drop night temperatures to $14-16{ }^{\circ} \mathrm{C}$. At these temperatures activity was substantially decreased but we still observed occasional basking and feeding continued albeit at a lower rate. Had we adopted much lower temperatures then the lizards would have been forced to brumate but according to Wilms (2005) U. geyri do not require an extended winter brumation (Wilms, 2005).

Many species of Uromastyx have been kept at BWCP over the last 20 years including $U$. benti, $U$. nigriventris, $U$. ocellata and $U$. dispar maliensis with little reproductive success. A clutch of 18 fertile eggs from $U$. benti hatched from wild caught adults but the breeding success was never repeated. A clutch of 12 eggs were incubated from $U$. $d$. maliensis but the individuals died as they were hatching. Historically, Uromastyx at BWCP were kept under UVB lighting but the amount of UVB they were exposed to was never tested and basking temperatures were $<40{ }^{\circ} \mathrm{C}$. The $U$. $d$. maliensis were kept in a large display (approx. $3 \times 1.5 \times 1.5 \mathrm{~m}$ ) so that maintaining temperature $>40{ }^{\circ} \mathrm{C}$ was problematic. Specimens were observed basking for most of the day and only left the basking site to feed. It is likely that our changes to husbandry including higher basking temperatures, better visible light, appropriate UVB provision, diet and incubation techniques have enabled $U$. geyri to reproduce in captivity annually.

Our method of husbandry has continued without change 


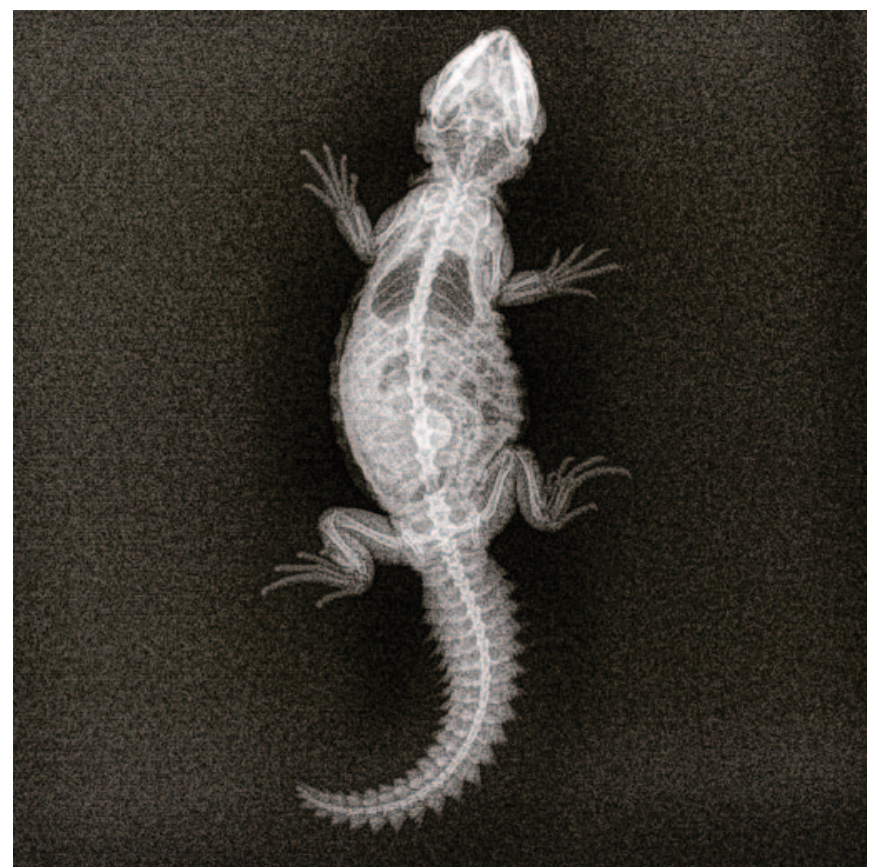

Figure 4. Radiograph of an 18 month U. geyri

since the breeding success described here. In 2019, as a check on our husbandry methods it was decided to use radiographs to make direct observations on skeletal development. Radiographs were taken of the dorsum of four 18 month old $U$. geyri. All specimens were conscious during the procedure and placed in a small clear container to restrict movements. The skeletons of all four specimens appeared healthy (Fig. 4). This suggests that the current husbandry of the juveniles was satisfactory and should be continued (Archer, K. pers. comm.)

According to Species 360 (2020), there are 41 zoological institutions around the world keeping $U$. geyri with a total of 79 individuals. BWCP is currently the only institution regularly breeding this species. We hope that if other institutions use the husbandry methods describe here they will be able to breed this species and so maintain viable captive populations.

\section{ACKNOWLEDGEMENTS}

Thank you to Johannes Els, Chris \& Ayesha Thompson and James Hicks for correspondence and for sharing relevant literature. Huge thank you to Birmingham Wildlife Conservation Park Manager, Les Basford, and keeper, Gareth Davies, for helping with advice, egg collection and maintenance during my absence. Thanks to Karen Archer from International Zoo Veterinary Group (IZVG) for allowing the reproduction of the radiograph image from the archives. Huge thank you to Benjamin Tapley from Zoological Society of London and Kinga Awruk for reviewing the original manuscript.

\section{REFERENCES}

CITES (2020) Convention of International Trade in Endangered Species. https://cites.org/eng/node/25522 (accessed May 2020)

Papenfuss, T. (1969). Preliminary analysis of the reptiles of arid central West Africa. The Wasmann Journal of Biology 27: 249-325.

Schleich, H.H., Kästle, W. \& Kabisch, K. (1996). Amphibians and Reptiles of North Africa. Koeltz, Königstein, Germany, $627 \mathrm{pp}$.

Species360 (2020). Version 2.3. https://zims.species360.org. Downloaded on 08 March 2020.

Turnbull, D. (2012). Breeding Uromastyx geyri (in the UK). The Herptile 37: 120-126.

Wilms, T. (2005). Uromastyx. Natural History, Captive Care, Breeding. Offenbach, Herpeton

Wilms, T. (2007). Ursachen und Ausmaß der Bedrohung von Domschwanzagamen - Versuch einer Bestandsaufnahme. Draco 31: 75-80.

Wilms, T., Wagner, P. \& Niagate, B. (2018). Uromastyx geyri. The IUCN Red List of Threatened Species 2018: e.T198536A2531409.https://dx.doi.org/10.2305/IUCN. UK.2018-2.RLTS.T198536A2531409.en. Downloaded on 05 January 2020.

Wilms, T., Bohme, W., Wagner, P., Lutzmann, N. \& Schmitz, A. (2009). On the phylogeny and taxonomy of the genus Uromastyx Merrem, 1820 (Reptilia: Squamata: Agamidae: Uromastycinae) - Resurrection of the genus Saara Gray, 1845. Bonner Zoologische Beitrage 56: 55-99. 